\title{
Gestión municipal participativa: entre la nueva gerencia pública y la gobernanza democrática*
}

Montecinos, Egon**

\section{Resumen}

Este ensayo realiza una revisión crítica de los principales fundamentos teóricos del concepto de gestión municipal participativa. Se revisa el marco teórico de dos de sus principales fundamentos, la nueva gerencia pública -principal modelo inspirador de la modernización del Estado en América Latina-y del emergente modelo de gestión llamado gobernanza democrática. El objetivo de dicha revisión es identificar los principales elementos teóricos de cada modelo que permiten configurar el concepto de gestión municipal participativa crecientemente utilizado en América Latina. La principal conclusión que arroja este ensayo es que el concepto de gestión municipal participativa tiene una base teórica de carácter híbrido que permite responder a la doble demanda que hoy se realiza a los municipios en América Latina: eficiencia y democracia. La metodología utilizada fue revisión bibliográfica de literatura especializada.

Palabras clave: Gestión municipal participativa, gobernanza democrática, participación ciudadana.

Recibido: 06-09-11. Aceptado: 02-04-12

* Paper construido en base a la revisión bibliográfica correspondiente a la primera etapa metodológica del proyecto FONDECYT 1110519 titulado "Democracia y presupuesto participativo en América Latina. Tensiones y complementariedades con la democracia representativa. Los casos de Chile, Argentina, Uruguay, Brasil, Perú y República Dominicana".

** Profesor Investigador del Centro de Estudios del Desarrollo Regional y Local de la Universidad de Los Lagos. Osorno, Chile. Actualmente se desempeña como Vicerrector de Planificación y Desarrollo de la misma casa de estudios. Trabajador Social. Magíster en Ciencias Sociales. Doctor en Ciencias Sociales, mención Ciencia Política. 


\title{
Participative Municipal Management: Between New Public Management and Democratic Governance
}

\begin{abstract}
This paper presents a critical review of the principal theoretical foundations of the concept of participative municipal management. The theoretical framework for two of its main foundations is reviewed: new public management - the principal inspiration for modernizing the State in Latin America - and the emergent management model called democratic governance. The objective of this review is to identify the principal theoretical elements for each model that make it possible to configure the concept of participative municipal management, increasingly used in Latin America. The main conclusion is that the concept of participative municipal management has a hybrid theoretical basis that allows it to respond to the double demand currently being made in Latin America municipalities: efficiency and democracy. Methodology was a bibliographic review of specialized literature.
\end{abstract}

Keywords: Participative municipal management, democratic governance, citizen participation.

\section{Introducción}

Sabido es que uno de los grandes desafíos que hoy enfrentan los municipios en América Latina, es que deben responder y hacerse cargo de múltiples necesidades de su territorio. Por otro lado, en la actualidad estas necesidades deben ser abordadas con un sentido de eficiencia y en un contexto de profundización democrática, que permita darle legitimidad a la acción pública desarrollada en el ámbito local. Esta realidad ha hecho que el concepto de gestión municipal participativa (en adelante GMP) esté tomando mayor fuerza entre actores políticos provocando una creciente tensión teórica y práctica entre eficiencia técnica y democracia, lo cual hace complejo encontrar consenso sobre la forma más adecuada en que los municipios y los actores políticos deberían enfrentar estos desafíos.

Esta valorización del concepto de GMP, se debería fundamentalmente a una especie de falta de respuestas que no encuentran los municipios en el modelo predominante de la nueva gerencia pública (inspirador de la modernización del Estado en América Latina), ya que parece ser que no basta con hacer la gestión de manera eficiente, eficaz y de calidad, sino que la participación activa de los ciudadanos en el desarrollo de sus territorios hace imperante pensar en modelos de gestión que pongan también atención de manera sustantiva en la relación democrática y vinculante entre las instituciones y los ciudadanos. De esta tensión surge la necesaria pregunta que orienta este ensayo, ¿cuáles son los modelos más adecuados para hacer una gestión municipal eficiente y democrática sin desmedro de una sobre la otra? En este ensayo, se plantea la hipótesis de que el concepto de GMP es la respuesta más adecuada y pertinente para abordar dichos desafíos, ya que conceptualmente no descuida la eficiencia y la eficacia, pero pone espe- 
cial atención en conciliar este estilo con uno democrático, incluyente y empoderante de los ciudadanos.

No obstante, en la literatura no se observa un examen acucioso sobre los fundamentos teóricos del concepto de GMP, de ahí que este ensayo se entiende como un primer esfuerzo y aporte por avanzar en una configuración de dicho concepto. Las preguntas específicas que se intentan escudriñar son ¿Cuáles son los fundamentos teóricos que se encuentran tras el concepto de gestión municipal participativa que se utiliza en América Latina? ¿Cuáles son las particularidades del concepto de gestión municipal participativa?

La metodología empleada fue la revisión bibliográfica de la literatura especializada con el fin de delimitar el concepto de nueva gerencia pública -principal marco teórico inspirador de la modernización municipal en América Latina- indagando sus fuentes teóricas y las diferentes corrientes que se desprenden de ella. Se intenta delimitar sus principales características haciendo especial alusión a la idea de "reinvención del gobierno" (Osborne y Gaebler, 1992: 25) y la relación que tienen sus principales propuestas con la idea de eficiencia técnica en la gestión municipal en particular. A partir de esto se recapitula los puntos fundamentales que plantea en particular la idea de la reinvención del gobierno.

Posteriormente, se desarrolla el concepto de gobernanza, en particular el concepto de gobernanza de proximidad, aclarando sus principales ideas y conceptos, realizando una distinción conceptual y teórica con la idea de la nueva gerencia pública. También se retoma la aportación que hacen algunos autores (Blanco y Gomá, 2002a; 2002b; 2003b; Brugué, 2001; Cabrero, 2008; Font, 2001) sobre la idea de la "revalorización" y "politización" de los espacios locales y sus instituciones (como por ejemplo las municipalidades) así como la ampliación de la agenda de políticas públicas que deben abordar. Se dejan planteados los principales elementos teóricos que podrían estar indicando que tras la apertura democrática de los municipios en América Latina, se encuentra un germen teórico inspirador de una modernización municipal de carácter político y que emergería desde abajo, desde lo local, y no desde el centro político como ha sido el proceso en general en América Latina, inspirado en las ideas de la nueva gerencia pública.

Se concluye con los elementos esenciales del concepto de gestión municipal participativa y su carácter integrador de los elementos de ambos modelos teóricos de gestión que aquí se revisan, eficiencia y democracia.

\section{Los fundamentos teóricos de la nueva gerencia pública}

Durante los últimos años han sido numerosos los aportes teóricos y prácticos que han intentado modificar los parámetros organizativos y el estilo de gestión del sector público (Barzelay, 2001: 14). Por ende, cuando se hace alusión a la denominada administración pública tradicional (Ramió, 2001: 65) o administración pública progresiva (Arellano, 2004a: 43) se coincide en encontrar conceptos como burocracia u organización jerárquica en donde cada unidad tiene responsabilida- 
Gestión municipal participativa: Entre la nueva gerencia pública y la gobernanza ...

Montecinos, Egon

des claramente delimitadas y reguladas mediante reglas, normas y mecanismos de control vertical. Claramente estas exigencias y supuestos administrativos fueron la solución a los problemas de la época derivados de la modernidad racionalizadora que se manifestaba en el dominio de la eficiencia, la predictibilidad, la calculabilidad y el control tecnológico (Ramió, 2001: 68). Ciertamente este modelo ha desarrollado disfunciones muy importantes que tienen como resultado la falta de adaptación de las organizaciones públicas con las características del contexto socioeconómico actual.

Después de numerosos intentos por cambiar o modificar los parámetros organizativos de la administración pública tradicional (estilo Weberiano) la propuesta que más se ha consolidado o que mejor se ha adaptado al nuevo "habitat" (Arellano, 2004b) de la era de la informativización ha sido la Nueva Gestión Pública o Nueva Gerencia Pública (Aguilar 2004 y 2005). Este nuevo contexto socioteconológico entre otras cosas, ha roto con varias de las restricciones tecnológicas que la burocracia weberiana enfrentó. Es por ello que a juicio de Arellano (2004b), ni la nueva Gestión Pública se ha impuesto por la capacidad o racionalidad de sus ideas, ni es una serie ordenada de ideas enteramente nuevas, ni la vieja administración pública ha dejado de funcionar o dar respuestas a problemas prácticos (Arellano, 2004b). Más bien se trata de una recreación de los problemas gubernamentales contemporáneos que ha realizado importantes apuestas analíticas y políticas que está cambiando la faz de la administración pública.
Los abordajes que han hecho los teóricos de la gestión pública provenientes de disciplinas como la ciencia política o la administración pública han sido diversos, por ejemplo, Aucoin (1995: 22) sostuvo que la Nueva Gestión Pública es un argumento doctrinario en relación al diseño organizacional que se apoya en las ideas del Nuevo Institucionalismo Económico y en visiones respecto de cómo mejorar el desempeño de las organizaciones de gobierno. Por su parte, Barzelay (1998 y 2001) con su paradigma posburocrático desarrolla un argumento doctrinario acerca de las mejores reglas y rutinas para el buen funcionamiento de las agencias administrativas centrales. Por su parte, Moore (1995) elaboró un argumento doctrinario sobre el rol de los gerentes públicos. Hood y Jackson (1991: 55) en su momento se refirieron a la NGP como un punto de vista sobre el diseño organizacional en el sector público (que de acuerdo con Barzelay, 2001 lo caracterizaron como un argumento administrativo). Últimamente Arellano (2004b: 42), realiza la distinción en torno a las bases teóricas de la Nueva gestión Pública, las cuales estarían arraigadas principalmente en el nuevo institucionalismo económico, en la elección racional y en bases teóricas del desarrollo organizacional.

De esta manera, dentro del estudio de la administración pública se volvían fundamentales conceptos como el de institución, las que cobraban relevancia ya que con ellas se podían suprimir los altos costos de transacción derivados de la opacidad gubernamental y al mismo tiempo solucionar los problemas de agencia y eficiencia derivados de la falta 
de responsabilidad en la función pública por los resultados de las decisiones y políticas públicas implementadas. José Ayala (1999: 15) indica que Coase en 1937 inicia el estudio de los costos de transacción la cual es retomada por WiIliamson en 1975 quien por medio del estudio de los costos de transacción desarrolla la teoría de la organización interna conocida como teoría de la firma, y además, entre otras cosas, analiza la conveniencia de utilizar mecanismos de mercado versus relaciones de jerarquía para la realización de contratos o transacciones (Ayala, 1999: 16).

Es así como el nuevo institucionalismo económico y la elección pública a través de sus diferentes preocupaciones teóricas y empíricas con respecto al Estado y la administración pública y su rol en la economía, abrieron teóricamente el estudio de las burocracias y reconocen la importancia de rescatar a las instituciones como factores explicativos del desempeño de las burocracias y de sus funcionarios

Ante este contexto teórico y ante las demandas de mayor eficiencia y eficacia exigidas al Estado se comienza a generar la necesidad de legitimar su existencia. Ya no bastaba con proveer servicios o tener el intento de buscar un beneficio colectivo, ya la legitimidad no recaía en el qué o en el cuánto sino que ahora recaía en el cómo (Ramírez y Ramírez, 2004: 105). Una de las propuestas que aborda el "cómo", y que se enmarca en el amplio concepto de nueva gestión pública, es la llamada "reinvención del gobierno" (Osborne y Gaebler, 1992), la cual ha sido el enfoque predominante en la modernización del Estado y en particular de las municipalidades en América Latina, las cuales inspiradas en este enfoque se sumaron a partir de los 80 " en un conjunto de reformas principalmente de carácter administrativo.

\section{Aportes de la "reinvención del gobierno" al concepto de gestión municipal participativa}

La reinvención del gobierno y su popularidad en los Estados Unidos se debe al impulso teórico del libro de Osborne y Gaebler, la "reinvención del gobierno" (versión en inglés de 1992) y al impulso político dado el "Informe Gore" el cual en uno de sus aparatados señalaba lo siguiente "es necesario tomar el timón más que los remos", delegando autoridad sustituyendo normas y regulaciones por incentivos, formulando presupuestos basados en resultados, exponiendo las operaciones del gobierno a la competencia, buscando soluciones de mercado más que soluciones administrativas y cuando ello fuese posible midiendo el éxito de las acciones de gobierno en términos de satisfacción al usuario (Jones y Thompson, 1999: 235).

Jones y Thompson (1999) resumen la propuesta de la reinvención del gobierno en las cinco "R" que para ellos son reestructuración, reingeniería, reinvención, realineación y reconceptualización. El resultado de la secuencia de las cinco " $R$ " seria un gobierno innovador, eficiente y efectivo. Estas ideas vienen a coronar de alguna manera la necesidad de realizar cambios significativos en la burocracia tradicional y en la cultura burocrática tal como ya lo había realizado Barze- 
Gestión municipal participativa: Entre la nueva gerencia pública y la gobernanza ...

Montecinos, Egon

lay (1998). Para impulsar este proceso de cambio dentro de las administraciones públicas tradicionales se requiere la "reestructuración" la cual se refiere en lo sustantivo a eliminar todo aquello que no aporte valor al servicio o producto suministrado al consumidor. Esto puede resultar en procesos de considerable delegación de autoridad de responsabilidades y de toma de decisiones con respecto a las operaciones cotidianas.

Respecto a la idea de reingeniería se centra más en "empezar de nuevo" que en tratar de "arreglar" los problemas existentes mediante soluciones parciales o temporales. Esta situación exige pensar acerca de procesos y no acerca de funciones y posiciones establecidas en las jerarquías organizacionales con el claro objetivo de alcanzar una mayor satisfacción del consumidor, un mejoramiento de la calidad del servicio y una mayor eficiencia medida en términos de tiempo y costo. La reingeniería exige también adecuarse las nuevas tecnologías de la información para ponerlas al servicio de la misión de la organización.

El objetivo final de la reingeniería es el incremento de la satisfacción del usuario, es decir de los resultados. La reducción del tiempo del ciclo y de los costos no son fines en sí mismos. Más bien son el resultado de mejores procesos de trabajo. Los criterios de medición son críticos para determinar si la reingeniería es exitosa, y por consiguiente, los métodos para la evaluación de los resultados y para la comparación de los mismos con los alcanzados por los procedimientos utilizados anteriormente, tienen que ser elaborados como parte del esfuerzo de reingeniería.
Lo que se denomina "reinvención" requiere pensamiento estratégico y planificación para desplazarse hacia el desarrollo de nuevos mercados y métodos de suministro de servicios. En lo esencial, la reinvención evalúa y hace cambios abarcativos en el servicio al cliente de la organización y en la estrategia del mercado de productos, particularmente en lo relativo a la competencia o a la amenaza de competencia. Esta transición es esencial para la supervivencia de la organización en un mundo siempre cambiante y más competitivo.

Esta reinvención requiere que las organizaciones públicas actúen con una orientación de planificación estratégica de largo alcance el cual es uno de los ingredientes clave para el éxito de la reinvención. Inicialmente, los gerentes públicos necesitan comprender la definición de mercadeo como algo más que publicidad y ventas.

En cuanto a la "realineación" tiene serias implicaciones para la rendición de cuentas y el presupuesto de la organización, por ejemplo, diferentes tipos de contabilidad y de presupuesto deberían ser empleados para diferentes propósitos. La realineación es, en esencia, la implementación de la estrategia de reinvención. Sin embargo, mientras que la reinvención tiene que ver con cambios en la forma de operar de la organización en el mercado externo, la realineación se centra en el cambio en el interior de la organización.

Finalmente la "reconceptualización" enfatiza pensar creativamente acerca de los mercados, los clientes, los productos y la organización del trabajo en las organizaciones públicas. Reconceptualizar exige desplazarse a un "análisis rápi- 
do" para la toma de decisiones organizacionales y aprender a pensar creativamente acerca de los problemas difíciles. La clave de la reconceptualización es el aprendizaje de cómo infundir una nueva manera de pensar a la gerencia pública para crear autoaprendizaje, y una organización con capacidad de adaptación y forjadora de conocimiento. La reconceptualización requiere de una mejor y más rápida evaluación del desempeño del servicio, utilizando la investigación por encuestas y otras técnicas, así como una estimación más rápida de cómo mejorar la estrategia de mercado y del servicio.

Estas cinco " $R$ " también se pueden resumir en 10 puntos que los propios autores Osborne y Gaebler (1992) apuntan. El primero de ellos lo denominan un gobierno catalizador el cual implica transformar el estilo de gobierno tradicional en uno facilitador, promotor, coordinador, que armonice y active las iniciativas de los sectores privados, comunitarios y otras organizaciones no gubernamentales para la búsqueda de soluciones a los problemas de la sociedad. Para lograr ese objetivo se tienen que, distinguir claramente entre "llevar el timón o remar". La idea de gobierno competitivo se relaciona con exigir criterios de competencia en la prestación de servicios mediante la eliminación de los monopolios gubernamentales y la liberación de las fuerzas del mercado. Promover la competencia entre proveedores (sector público vs. sector privado o viceversa) tendrá el efecto de mejorar la productividad, crear mayor conciencia sobre los costos y los servicios y la obligación de responder con un servicio de calidad a los consumidores. La competencia también estimula la inno- vación, la eficiencia y la responsabilidad de la gerencia pública, pero más importante aun: crea un sentido de mejor aprovechamiento del presupuesto público (Santana y Negrón, 1996: 155).

El gobierno inspirado por misiones, a diferencia de las organizaciones públicas tradicionales, tiende a minimizar las reglas y ponen su enfoque en definir claramente su misión y objetivos. Una vez que la misión esté claramente definida, la gerencia puede determinar la estrategia y diseñar los mecanismos para su implantación de una manera más efectiva. En este sentido los autores Osborne y Gaebler, (1992) presentan una gran variedad de ejemplos tendientes a demostrar que las organizaciones orientadas por misiones son más innovadoras, eficaces y productivas. El gobierno orientado hacia los resultados significa que el desempeño se debe evaluar por la calidad de los resultados y no necesariamente por el fiel cumplimiento de los procesos formales. Es necesario medir los logros alcanzados, establecer indicadores cuantitativos y cualitativos, y vincular los incentivos salariales con el desempeño de los empleados. El gobierno orientado hacia los clientes tiene el fiel propósito de servir a sus ciudadanos, sin embargo en la burocracia tradicional los fines se convierten en medios de perpetuación. Con base en la filosofía de calidad total, argumentan que la mejor forma para obtener calidad es logrando satisfacer las necesidades o deseos del cliente. Abogan por que se redefina al ciudadano como cliente (o comprador de servicios). Esto significa que la mejor manera de hacer que las agencias respondan a las necesidades de sus clientes es proveerles 
Gestión municipal participativa: Entre la nueva gerencia pública y la gobernanza ...

Montecinos, Egon

los recursos (dinero) a éstos y permitirles que seleccionen la mejor opción entre los proveedores de servicios.

El gobierno descentralizado consiste en otorgarle mayor grado de autoridad para tomar decisiones a los funcionarios en los niveles más bajos de la organización, esto implica delegar autoridad y conferir mayor poder decisional a las unidades y empleados. Es decir, acercar las decisiones a los niveles más próximos a los denominados clientes, reducir las jerarquías burocráticas y fomentar la participación y el trabajo en equipo. El gobierno de la comunidad, intenta fortalecer las comunidades y la participación de los ciudadanos en las decisiones gubernamentales. Se parte del supuesto de que la comunidad tiene mayor compromiso y que entiende mejor sus problemas que los burócratas profesionales. En síntesis, significa reducir el poder a los funcionarios y devolvérselo a los ciudadanos. EI gobierno previsor tiene como función principal anticipar los problemas, prevenir para evitar remediar. Se basa en la necesidad de la planificación estratégica, lo cual significa visualizar el futuro de la organización a los fines de formular su misión, identificar los problemas más urgentes o prioritarios, y adoptar los objetivos, decisiones y acciones para alcanzarla. EI gobierno orientado al mercado significa que debe explorar la idea de utilizar los mecanismos del mercado para ofrecer servicios públicos. Se parte del supuesto de que el mercado puede ser estructurado para conseguir metas públicas y evitar que los programas gubernamentales respondan a decisiones políticas.

Todos estos elementos teóricos, sin duda, influyeron en la modernización del Estado en América Latina, y particularmente en los procesos impulsados desde el Estado hacia las municipalidades o gobiernos locales. No obstante, y dada la gran diversidad de realidades a las que se enfrentan los gobiernos locales, las reformas gerencialistas, especialmente las impulsadas en los espacios locales, no han alcanzado los resultados esperados en materia de eficiencia y democracia, en el sentido de ofrecer una solución integral a los problemas que enfrentan los gobiernos locales en América Latina.

Al respecto, algunos estudios indican que se ha avanzado con un poco mas de resultados en la provisión de los servicios sociales, que en el fortalecimiento de la gobernabilidad democrática de la sociedad civil en América Latina (Cunill, 1991 y 1997; Rufián y Palma, 1993; Huerta et al., 2000; Finot 1998, 1999 y 2003; Delamaza et al., 2004; Hernández, 2001). Esta última variable de gobernabilidad democrática, que ha resultado ser la más compleja de abordar por el enfoque gerencialista, implica que los actores sociales tengan cierta capacidad o poder de influencia en las decisiones que le conciernen, se parte del supuesto de que la vida local constituye el medio más natural para fortalecerla, por lo que dicho poder o influencia en la decisión debe ser foco de atención de dicho modelo.

\section{La gobernanza: Aspectos distintivos de un concepto difuso}

No cabe duda que desde mediados de los 90 se ha venido una nueva oleada desde Europa y que ha arremetido fuerte- 
mente respecto a tratar de alcanzar un consenso en torno a que la eficacia y la legitimidad del actuar público se fundamentan en la calidad de la interacción entre los distintos niveles de gobierno, y entre éstos y las organizaciones empresariales y de la sociedad civil (Prats, 2003: 245; Aguilar, 2004: 2; 2005: 5). Estos nuevos modos de gobernación que se reconocen crecientemente como "gobernanza" no significan anulación, sino modulación y reequilibrio de los modelos burocráticos tradicionales y del de gerencia ${ }^{1}$.

La clave para la gobernanza está en saber organizar un espacio público deliberativo basado en normas procedimentales que retroalimenten la confianza en la estructura de interdependencia (Prats, 2003: 255). Hoy sabemos que nadie tiene el conocimiento suficiente para resolver unilateralmente cuestiones complejas y que los límites de nuestro conocimiento nos obligan a interactuar para buscar soluciones provisionales siguiendo procedimientos que nos permitan aprender permanentemente y adaptarnos a los resultados del aprendizaje.

Por encima del enjambre de opiniones doctrinales propias de la etapa de nacimiento de un nuevo paradigma, la gobernanza no elimina la necesidad de los gobiernos, aunque sí replantea sus roles, formas organizativas y procedimentales, los instrumentos de gestión pública, las competencias de los funcionarios y las capacidades de dirección política de la administración.

Uno de los aspectos potencialmente conflictivos es la relación entre democracia y gobernanza, ya que nos plantea una forma diferente de relación entre la institucionalidad pública y la ciudadanía, que supera la tradicional participación pasiva o consultiva que promueve el gerencialismo. Para que una estructura interactiva de gobernanza sea democrática y potencialmente incluyente, es preciso que el conjunto de intereses concernidos por el proceso decisional se encuentren simétricamente representados en el proceso decisional público. Una asociación entre sector público y privado puede constituir gobernanza pero no será democrático sino en la medida en que los intereses sociales tengan oportunidad efectiva para organizarse, informarse y participar en la interacción decisional. La gobernanza no es solamente ni lobby ni participación. Estos conceptos pueden ser plenamente operativos en los modos de gobernación representados por la burocracia y la gerencia, pues por sí no implican interacción decisional. Si las estructuras de interacción decisional características de la gobernanza permiten la exclusión o el ninguneo de grupos de interés significativos, el riesgo de deslegitimación o desafección democrática es muy elevado.

1 Cabe señalar que los nuevos modos de gobernar tienden a llamarse de diversas maneras como por ejemplo, gobernanza (Mayntz, 1993), gobierno relacional (Blanco y Gomá 2003b; Brugué y Gomá 2001) o en redes de interacción público-privado-civil (Zurbriggen, 2004; Saidón, 1994). 
Gestión municipal participativa: Entre la nueva gerencia pública y la gobernanza ...

Montecinos, Egon

\subsection{La gobernanza de proximidad. Aportes para entender la gestión municipal participativa}

La gobernanza participativa y de proximidad es una propuesta teórica específica que emerge dentro de esta gran discusión en torno a la gobernanza ${ }^{2}$ y es propuesta por diferentes autores de la Universidad Autónoma de Barcelona, entre los que se puede destacar a Ricard Gomá, Quim Brugué, Joan Subirats, Ismael Blanco, Joan Font, entre otros. No se plantea como un simple cambio en la dimensión operativa del Estado sino como una transformación que afecta a la relación sustantiva entre el Estado y la sociedad civil y la entienden como "un espacio potencial de profundización democrática, a partir de dos vectores clave: la participación y la proximidad, es decir a través del fortalecimiento de redes pluralistas, abiertas e inclusivas y el fortalecimiento de los espacios locales de gobierno y la articulación de redes multinivel como componentes esenciales de liderazgo municipal" (Blanco y Gomá, 2003b: 13).

La importancia de esta propuesta es que la discusión de la articulación de actores de la gobernanza la lleva al espacio local, recuperando el rol político que les corresponde jugar tanto a los actores institucionales como a los actores políticos frente a la ampliación de las agendas locales provocada por el nuevo entorno altamente abierto y globalizado (Brugué et al., 2001: 30; Brugué et al., 2005: 8; Font, 2001: 14; Blanco y Gomá, 2003a: 48).

Esta perspectiva además de recuperar el rol político de los espacios locales, enfatiza en que la crisis de eficiencia que afecto a los Estados de bienestar fue una crisis que afectó tanto a las capacidades de los poderes públicos para otorgar respuestas eficaces y eficientes a las nuevas demandas, como una crisis de los fundamentos mismos de la legitimidad democrática de los Estados (Subirats, 2001: 33; Brugué et al., 2001; 10; Blanco y Gomá, 2003b: 14). Esta crisis que afecta a los poderes públicos se relaciona con la crisis en los pilares básicos del Estado de bienestar tradicional, la cual se ha provocado por una transición hacia una economía pos-industrial y globalizada. Esto ha hecho que el Estado se muestre cada vez más incapaz para enfrentar los problemas que se le plantean. Se ha generado también un desbordamiento provocado por un proceso de transnacionalización de los problemas y las oportunidades de gobierno (Blanco y Gomá, 2002a: 15).

Frente a esta situación teórica y práctica, la ideología neoliberal comenzó a construir un discurso que cuestiona la capacidad real que tienen los gobiernos para dirigir y controlar el cambio social y

2 Para profundizar sobre el tema de la gobernanza se recomienda ver Mayntz (1993, 2001, 2002); Rhodes (1997); Winograd (2002); Kooiman, (1993): Bovaird, (2002); Bulmer (1994); Comisión Europea (2001); Whittingham (2005). No obstante en este ensayo, no se da esta discusión sino que se da específicamente al nivel de la gobernanza de proximidad. 
proponen el retorno al mercado como la única forma plausible eficiente y efectiva de regulación de las necesidades sociales (Blanco y Gomá, 2003b: 15). Es por eso, prosiguen los autores, en la actualidad va tomando forma una propuesta teórica de un modelo de bienestar altamente comprometido con los valores de la ciudadanía social pero crítico de los componentes burocráticos del esquema tradicional.

Adicionalmente, las democracias comienzan a ser cuestionadas en un nuevo contexto cultural marcado por el predominio de nuevos valores postmaterialistas (Inglehart, 1999) en la que los individuos se muestran cada vez menos dispuestos a desempeñar papeles pasivos, y por el contrario, reivindican un papel más activo y protagónico en los procesos políticos (Blanco y Gomá, 2003: 25) ${ }^{3}$.

De esta manera el gobierno democrático tradicional se encuentra con dificultades crecientes para reaccionar de manera eficaz y eficiente ante un entorno cada vez mas complejo y la legitimidad democrática de las instituciones públicas se va deteriorando ante una ciudadanía cada vez más reflexiva y crítica, con nuevos valores sociales que no pueden satisfacerse con la simple provisión tecnocrática de servicios públicos (Borja, 2002: 59; Cabrero 2008: 23; Blanco y Gomá, 2003b: 7).

Las dificultades del modelo de gobierno tradicional para enfrentarse a esta nueva realidad se pueden resumir en lo que los autores Blanco y Gomá (2003a y 2003b: 25) denominan 4 ejes dinámicos. Una dificultad de tipo cognitiva la cual se refiere a la dispersión del conocimiento y la información y la consecuencia de que ningún actor pueda llegar a poseer un monopolio absoluto de ella. Es por ello que los orígenes, las causas y las soluciones a los problemas públicos así como las intervenciones de las instituciones son difícilmente abordables desde certezas cognitivas inequívocas.

En segundo lugar existen dificultades relacionadas con la autoridad, lo que significa asumir que las políticas públicas se desarrollan en un escenario donde los implementadores (en este caso los municipios) no son sujetos absolutamente subordinables a las órdenes dictadas por las elites centrales, sino que, muy por el contrario mantienen cierta discrecionalidad que les permite influir en su orientación. Otra dificultad se relaciona con la probabilidad de que las intervenciones públicas provoquen ciertas externalidades sobre actores o niveles territoriales que no han sido previamente representados como sujetos y objetos del proceso de toma de decisiones.

Por último, las dificultades se asocian con la complejidad de los valores, intereses y las preferencias individuales y colectivas que se encuentran en juego, la selección de las mejores alternativas ya no dependerían de criterios de corte técnico y racionalista sino que también de un proceso eminentemente político en don-

3 Una idea similar se desarrolla en torno al caso Chileno en el libro de Delamaza et al. (2004: 14) Innovación y Ciudadanía en la Gestión Territorial: El rol de los Municipios. 
Gestión municipal participativa: Entre la nueva gerencia pública y la gobernanza ...

Montecinos, Egon

de los diversos actores tratan de imponer sus valores e intereses particulares que a su vez son variables e inestables.

Precisamente son frente a estas dificultades contextuales a las que se ve enfrentado el modelo tradicional de gobierno desde donde emerge la propuesta de gobernanza de proximidad y participativa, donde el municipio está llamado a cumplir un rol articulador, deliberativo y relacional en el territorio y no sólo operador y administrador de políticas públicas locales.

\subsection{La dimensión de proximidad de la gobernanza}

Uno de los aspectos importantes que rescata el enfoque teórico de gobernanza participativa y de proximidad es avanzar hacia un enfoque de gobierno relacional que sitúa a la gestión municipal en términos de deliberación e implicación ciudadana pluralista en las decisiones públicas. Esta idea intenta ir mas allá de la concepción restringida de la gobernanza como escenario de negociación de intereses entre grupos de presión, ya que valora los aspectos de proximidad y de conformación de redes local/global mas allá de los intentos de reconstrucción de capacidades nacional estatales de gobierno (Blanco y Gomá, 2003b: 7).

La inevitable situación de que el Estado se encuentra cediendo y volviendo a situar a la baja sus capacidades de gobierno ante el fortalecimiento del eje territorio/globalidad podría llevar a pensar que esto ha traído consigo un cierto debilitamiento de la esfera local. No obstante y de acuerdo con Cabrero (2008: 19) se ha generado una situación diametral- mente opuesta ya que lo que él denomina una "revolución silenciosa" de los gobiernos locales, ha hecho expandir y profundizar la agenda de las políticas públicas de los mismos. En este proceso, los gobiernos locales se ven forzados a innovar en materia de gestión, a generar consensos y vigorizar el capital social y a construir redes de actores (Cabrero, 2008: 21).

De esta manera, de la mano de la ampliación de las agendas locales en materia de políticas públicas y de la asunción de nuevos roles estratégicos, los espacios locales tienden a la politización de sus instituciones lo cual pone a los municipios en un proceso de superación de los tradicionales roles operativos, tanto del modelo burocrático tradicional como de las versiones gerencialistas recientes.

En este contexto, aparece la idea del gobierno de la "proximidad" configurado en "redes", la cual nos sugiere que el territorio no es únicamente una realidad física sino también relacional, el cual se convierte en un elemento estructural que apoya la superación de la visión jerárquica y segmentada del gobierno tradicional.

Estas redes locales presentan 2 dimensiones. Una configuración horizontal con la presencia de múltiples actores sociales, privados y comunitarios y una configuración multinivel que articula espacios en los que confluyen, liderados por el nivel local, varios niveles territoriales de gobierno.

Respecto a las redes participativas horizontales, estas se caracterizan por superar las características de un sector público que actúa desde la autosuficiencia sin necesidad aparente de interactuar con otras esferas sociales. Las redes ho- 
rizontales de múltiples actores interdependientes, con relaciones más o menos conflictivas o consensuales y con distribuciones más o menos asimétricas de poder se transforman en los nuevos espacios de regulación social de gobernanza de proximidad (Blanco y Gomá, 2003b: 35). Más allá de las características de interdependencia y multipolaridad, las redes horizontales de gobernanza de proximidad pueden variar de acuerdo a cuatro dimensiones. La primera de ellas se refiere a su configuración básica, es decir, al numero de actores que la conforman y la intensidad de sus interacciones, la segunda se refiere a las relaciones internas de poder, especialmente referido al poder con que cuenta cada actor al interior de la red y los recursos con los que cuenta al interior de ella para alcanzar sus objetivos (recursos físicos, económicos, políticos o intelectuales). La tercera dimensión se asocia con la distribución de los intereses en juego así como la presencia de actitudes más o menos inclinadas a soluciones negociadas. Finalmente se encuentra la dimensión de la relación de la red con el entorno inmediato ${ }^{4}$.

Respecto a la configuración multinivel de las redes, esto quiere decir que las redes locales se insertan también en relaciones que atraviesan los múltiples ámbitos territoriales de gobierno. Esto refleja un nuevo escenario para entender las formas tradicionales de relaciones intergubernamentales se configura como un sistema en el que los gobiernos locales comparten con el resto de los niveles territoriales de gobierno definiciones de problemas y de políticas sobre agendas de temáticas amplias. En este caso el polo de proximidad se expresaría en la capacidad de los gobiernos locales de liderar, es decir de dotar de orientación estratégica las convergencias entre estos niveles de gobierno. La articulación de una red de multinivel es una cuestión de carácter político, será la deliberación abierta, la negociación y el aprendizaje lo que vaya conformando ciertas pautas y por lo tanto consolidando redes local/global con capacidad de afrontar problemas colectivos y satisfacer necesidades y expectativas ciudadanas (Blanco y Gomá, 2003b: 48; Ziccardi, 2009: 183).

La idea de proximidad se puede definir como un proceso en donde los actores políticos y burocráticos junto a la ciudadanía se potencian más y toman mayor fuerza en territorios donde las relaciones interpersonales, las confianzas mutuas, las tradiciones y los contactos directos cara a cara, cobran relevancia a la hora de tomar un gran acuerdo que de dirección al desarrollo y al crecimiento territo-

4 Blanco y Gomá tanto en los artículos de Reforma y Democracia № 26, (2003a) como en Gestión y Política Pública No 12/1 (2003b) así como en el libro de Gobiernos Locales y redes participativas señalan que de acuerdo a estas 4 dimensiones de la red se pueden producir 2 escenarios polarizados. Un primer escenario de redes seria poco complejo con más simetrías y puntos de acuerdo internos, pero también más consolidadas y decoradas al exterior. Un segundo espacio de redes más heterogéneas, desiguales y conflictivas pero también menos asentadas y más participativas. 
Gestión municipal participativa: Entre la nueva gerencia pública y la gobernanza ...

Montecinos, Egon

rial. Esto requiere de fuertes compromisos sociales, "ganas de decidir localmente", relaciones sociales asociativas $y$ orientadas por un rol político que le de cierta dirección a la acción municipal y territorial.

La dimensión de proximidad tendría una íntima relación con la formación de un proceso emprendedor e innovador que nace desde el municipio pero en interacción con los ciudadanos, en que el territorio y su población no son un receptor pasivo de políticas, estrategias y proyectos del Estado o de las grandes empresas transnacionales. De esta manera la dimensión de proximidad de la gobernanza emerge de un territorio socialmente construido y definido como comunidad con personas que poseen grados crecientes de pertenencia e identidad, con presencia de potencialidades, recursos, habilidades e iniciativas que permitan innovar en el ámbito local.

\subsection{La dimensión participativa de la gobernanza}

Cuando se habla de redes participativas se hace alusión a los siguientes aspectos: articulación de actores en torno a un proyecto compartido integrados en un marco político común, en donde se consensúan definiciones de problemas, se negocian prioridades, se intercambian recursos y se coopera para el desarrollo de objetivos y estrategias comunes.

La idea existente detrás de este paradigma de gobierno es reconocer la complejidad del entorno y tratar de gobernarla y no eliminarla y asumir la incertidumbre como un elemento intrínseco en el proceso político. Por ello, la tarea de gobernar ya no es sólo de unos pocos profesionales técnicos y expertos en determinadas materias, sino que se concibe como un proceso abierto, de aprendizaje social donde múltiples actores aportan sus conocimientos y vivencias de la realidad.

De acuerdo con Blanco y Gomá (2002a: 32; 2002b: 5; 2003b: 7; Delamaza, 2009: 14; Ziccardi, 2009: 183), los elementos que definen a una red participativa de gobernanza es la ausencia de un centro jerárquico capaz de fijar los procesos de gobierno de manera monopólica, ya que no se trata solamente de pluralismo y de más actores incorporados en el proceso decisional, sino que se trata también de dependencias mutuas entre los actores para resolver problemas, perseguir objetivos comunes y alcanzar ciertos resultados. Finalmente se requiere de cierta institucionalización para garantizar con estabilidad y rutinización las interacciones de los actores (Delamaza, 2009: 17; Ziccardi; 2009: 198). Es decir, los espacios generados para ello no bastan que estén supeditados a voluntades políticas de los gobernantes, sino que debieran estar garantizados o fortalecidos con diseños institucionales que ofrezcan al ciudadano un rol de garante de estos espacios, frente a la voluntad o decisión del gobernante por abrirlos.

\section{Conclusiones}

Tomando en consideración los dos enfoques teóricos revisados, la gestión municipal participativa se puede entender "como aquel estilo de gestión municipal que se inspira y fundamenta esencialmente en un proceso tecno-político de 
ajuste interno de la institución -municipio- con el fin de realizar de manera eficiente, eficaz y de calidad la prestación de bienes y servicios públicos al ciudadano, en un contexto donde éste ultimo goza de espacios vinculantes y permanentes de participación, que van desde la información, consulta, decisión, llegando hasta el control ciudadano de la propia gestión que desarrolla el municipio".

Se trata entonces de un doble desafío para los gobiernos municipales. Por un lado, realizar una gestión municipal eficiente, eficaz y de calidad y por otro lado, poner permanentemente en sus objetivos el fortalecimiento democrático a través de la participación de diversos actores en el proceso decisional y crear los marcos organizativos necesarios para el intercambio y la cooperación entre actores diversos, de convencer al conjunto de actores de los beneficios colectivos que se derivan de la participación en la red y de ofrecer incentivos necesarios para que se impliquen en ella.

De esta forma, la GMP tiene retos cruciales en lo que se refiere a funcionalidad municipal, ya que tiene el reto de construir capacidades para afrontar nuevas temáticas y satisfacer nuevas expectativas y en términos de legitimidad se presenta el desafío de la profundización democrática en clave más ciudadana y participativa.

No cabe duda que algunas experiencias -hasta ahora aún aisladas- desarrolladas por municipios en diferentes latitudes de América Latina, pueden estar acercándose a este definición conceptual, pero no representan las experiencias mayoritarias, ya que a más de una década de iniciada la modernización mu- nicipal en América Latina, se puede reconocer que la gestión municipal ha encontrado más nichos de éxito en aspectos operativos y de reducción de los costos de transacción que en aspectos democráticos y de participación ciudadana. Esta tendencia se traduce en iniciativas desarrolladas por municipios tales como optimización de gastos e ingresos, satisfacción del cliente, calidad y agilidad en el servicio, las cuales sin duda tienen una faceta claramente democrática y de ciudadanía, pero no son del todo suficientes para fortalecer y restablecer una relación entre Estado y comunidad debilitada en América Latina. En estas iniciativas todavía no se aprecia una apropiación de lo público por parte de la ciudadanía, ni un control social sobre la gestión pública municipal. En estas experiencias, el municipio ha tenido un rol como una unidad operadora del nivel central, sin capacidad de modificar las estructuras preestablecidas. La gestión se vuelve rígida y los criterios técnicos para orientar la gestión local cobran mucha mayor relevancia que la participación ciudadana. Como consecuencia, el municipio en todas las reformas impulsadas en la región, está llamado a cumplir un rol administrativo y no político, lo cual no significa que la participación democrática se encuentre ausente como política en la modernización municipal, sino que más bien es considerada en las decisiones gubernamentales como una estrategia instrumental que se utiliza para legitimar decisiones y proyectos previamente determinados. En este sentido, la mejor forma que utilizan los órganos del Estado para legitimar su intervención, es a través de los criterios técnicos y a través de la "consulta" para conocer las ne- 
Gestión municipal participativa: Entre la nueva gerencia pública y la gobernanza ...

Montecinos, Egon

cesidades y problemas de la comunidad y acercar de mejor forma las preferencias del ciudadano a las soluciones entregadas por el municipio.

Esta orientación eficientista, muy característica de la modernización y por ende del concepto de gestión municipal predominante hasta ahora, además entiende al ciudadano como un cliente y al municipio como una empresa, el cual debe "escuchar" y consultar para buscar y ajustar la mejor solución al problema, de esta forma asegurar que las preferencias de los ciudadanos sean abordadas y satisfechas por el nivel municipal. Entre otras cosas, se da por hecho que este "cliente" existe y que cuenta con gran parte de sus derechos civiles, políticos y sociales satisfechos.

Ambas ideas, la de "escuchar y consultar" a la comunidad compuesta por "clientes", responde a un criterio de eficiencia asignativa y se encuentran presentes en la implementación de las principales políticas de acción en la región. Esto provoca estilos de participación de corte consultivo, en donde el ciudadano toma parte sólo para intervenir en la etapa de diagnóstico, sin intervenir en el control y seguimiento de la política pública municipal.

Por su parte, el camino hacia una gestión municipal participativa implica necesariamente que el municipio entienda la gestión, no tan sólo como una cuestión que requiere mirar hacia al interior del aparato administrativo, en términos de hacer más eficiente la gestión, sino que también hacia fuera de él, es decir, mirar hacia el entorno territorial y los actores que lo componen, cuestión que conlleva cumplir una función de naturaleza política y deliberativa y no simplemente administradora en la gestión municipal. Este aspecto no implica que los criterios técnicos se sobrepongan como el eje sustantivo de la gestión local, ni se transformen en un fin en sí mismo, sino que implica que se transforman en los medios más idóneos para otorgarle viabilidad o legitimidad técnica a las prioridades definidas y decididas de manera democrática en y por la comunidad.

Cuando la gestión municipal se concentra únicamente en la eficiencia técnica, la participación de la ciudadanía se transforma en un medio instrumental para validar las necesidades y proyectos que resultan ser más viables para algunos actores, frecuentemente para quienes toman las decisiones. Este aspecto se vuelve contradictorio cuando al municipio también se le exige contribuir, a través de un trabajo participativo, al fortalecimiento de la ciudadanía y la democracia en una sociedad cada vez más diversa y compleja en términos de sus preferencias.

La GMP significa que la función operativa de la gestión municipal, se orienta por su irrenunciable función "política”, donde la participación democrática no se desprende ni se desvincula de la primera. La participación democrática, se pone al servicio de todo el proceso de la gestión municipal, es decir, desde la definición de prioridades y políticas, hasta la fiscalización de la gestión local, lo cual, además de implicar procesos de negociación y pacto, trae una clara implicancia en relación con el criterio de la eficiencia técnica de los proyectos locales. La relación entre actores locales deja de tener un carácter directivo de parte del municipio. 
Las decisiones finales sobre los proyectos a implementar ya no son tomadas solamente por el ejecutivo local o por la mesa técnica creada para tal efecto. Cuando los municipios asumen este rol político, de mediador y articulador, las reglas del juego que rigen a la gestión local tienden a ser pactadas entre actores políticos, actores municipales, actores sociales y los ciudadanos, lo cual implica flexibilidad de los instrumentos de planificación pero garantiza un control ciudadano sobre la gestión municipal. La tradicional autosuficiencia del municipio se ven contrarrestadas con la apropiación de esta modalidad de gestión en la comunidad.

En definitiva, la GMP se orienta por la capacidad de articulación, deliberación, influencia y liderazgo municipal sobre el conjunto de los demás actores integrantes del proceso. Esto no significa que los criterios técnicos dejan de tener relevancia ni pasan a un segundo plano, o que se provoque una dictadura de la política sobre la técnica. Lo que sucede es que dejan de ser fines en sí mismos y se transforman en medios al servicio de la legitimidad democrática de la política local, en este estilo de gestión los criterios técnicos adquieren un sentido pero como medio al servicio de la actividad deliberativa de la gestión pública local. Ambos criterios, eficiencia y democracia, resultan ser esencialmente relevantes pero uno se encuentra al servicio del otro, en este caso, la eficiencia técnica se encuentra al servicio de la deliberación democrática de la política local, ya que el proceso de participación e incidencia ciudadana no termina con la consulta sino que se extiende hasta la fiscalización de esos pro- yectos locales. En definitiva, el sentido de este rol político es que la deliberación democrática le otorga legitimidad a los objetivos municipales, los que posteriormente deberán ser desarrollados e implementados con la debida neutralidad y eficiencia técnica procurada por la "reinvención del gobierno".

\section{Referencias bibliográficas}

Aguilar, Luis (2004). Gobernabilidad/Gobernanza, Documento de Trabajo preparado para el curso de doctorado de FLACSO - México, promoción 2003 2006.

Aguilar, Luis (2005). Gobernanza y Justicia, Documento de Trabajo, FLACSO/México 2005, Consultado en Agosto de 2011 de la página web http://www.focal.ca/pdf/aguilar.pdf.

Arellano, David (2004a). Gestión Pública: Fuentes analíticas, críticas pertinentes y advertencias sobre su uso en Guerrero Omar (editor) Gerencia Pública: Una aproximación plural, Editado por UNAM, México.

Arellano, David (2004b). Nueva Gestión Pública: ¿Dónde está lo nuevo? Bases para el debate de la reforma administrativa en David Arellano (compilador) Más allá de la reinvención del Gobierno: Fundamentos de la Nueva Gestión Pública y presupuestos por resultados, Editorial Porrúa, México D.F.

Aucoin, Peter (1995). The New Public Management: Canada in Comparative Perspective, Montreal, Canada, Institute for Research on Public Policy.

Ayala, José (1999). Instituciones y Economía. Una introducción al neoinstitucionalismo económico, FCE, México D.F. 
Gestión municipal participativa: Entre la nueva gerencia pública y la gobernanza ...

Montecinos, Egon

Barzelay, Michael (1998). Atravesando la Burocracia: Una Nueva Perspectiva de la Administración Pública, Ciudad de México: Fondo de Cultura Económica.

Barzelay, Michael (2001). La Nueva Gerencia Pública. Un ensayo Bibliográfico paras estudiosos latinoamericanos. $\mathbf{R e}$ forma y Democracia, 19, Venezuela, CLAD, PP 9-44.

Blanco, Ismael; Gomá Ricard (2002a). Proximidad y Participación: marco Conceptual y Presentación de Experiencias en Blanco Ismael y Gomá Ricard (coordinadores) Gobiernos Locales y redes Participativas, Editorial Ariel, Barcelona.

Blanco, Ismael; Gomá Ricard (2002b). Presupuestos Participativos y Democracia Local: Una comparación entre las experiencias Españolas y Brasileñas. Biblioteca Virtual TOP.

Blanco, Ismael; Gomá Ricard (2003a). Gobiernos Locales y Redes Participativas: retos e innovaciones, Reforma y Democracia, 26, Venezuela, CLAD.

Blanco, Ismael; Gomá Ricard (2003b). La crisis del modelo de gobierno tradicional. Reflexiones en torno a la governance participativa y de proximidad, Gestión y Política Pública, Volumen 12, № 1, México D.F, Centro de Investigación y Docencia Económica, pp 5-42.

Borja, Jordi (2002). Ciudadanía y Globalización, Reforma y Democracia, 22, Caracas, CLAD.

Bovaird, Lofler; Parrado Diez (2002). Developing Local Governance Networks in Europe, Baden-Baden, Nomos Publishers.

Brugué, Quim et al. (2001). Redes, Territorios y Gobierno, Diputación de Barcelona, Barcelona.

Brugué, Quim; Gomá, Ricard (2001). El Gobierno del Territorio: Del Estado a la red en Brugué, Quim; et al. Redes, Territorios y Gobierno, Diputación de Barcelona, Barcelona.

Brugué, Quim; Gomá, Ricard; Subirats, Joan (2005). Gobernar Ciudades y Territorios en la sociedad de las redes, $\mathbf{R e}$ forma y Democracia, 32, Caracas, CLAD, pp 7-18.

Bulmer, Simon (1994). The Governance of the European Union: a New Institutionalist Approach, in Journal of Public Policy, 13/4; pp 351-380.

Cabrero, Enrique (2008). La Innovación Local en América Latina. Los Avances y los Desafíos en Cabrero et al., Innovación Local en América Latina, editado por el Centro de Investigación y Docencia Económica, CIDE, México.

Comisión Europea (2001). La Gobernanza Europea. Un Libro Blanco. Bruselas, Servicio de Publicaciones de la Comisión Europea.

Cunill, Nuria (1991). Participación Ciudadana: Dilemas y perspectivas para la democratización de los Estados Latinoamericanos. Editado por Centro latinoamericano de Administración para el Desarrollo CLAD, Caracas, Venezuela.

Cunill, Nuria (1997). Repensando lo público a través de la sociedad. CLAD/Nueva Sociedad, Caracas, Venezuela.

Delamaza, Gonzalo et al. (2004). Innovación y Ciudadanía en la gestión territorial: el rol de los municipios, Programa de Innovación y Ciudadanía, Santiago.

Delamaza, Gonzalo et al. (2009). Estado Actual y Desafíos para la Institucionalización de la participación ciudadana en Chile, en Delamaza, Gonzalo et al. (2009). Gestión Municipal Participativa. Construyendo Democracia Cotidiana, editado por Corporación Innovación Ciudadana y Universidad de Los Lagos, Santiago. 
Finot, Iván (1998). Descentralización del Estado y Participación Ciudadana en América Latina. Un enfoque crítico. CEPAL. LC/IP/R165.

Finot, Iván (1999). Elementos para una reorientación de las políticas de descentralización y participación en América Latina, Reforma y Democracia, 15, Caracas, CLAD.

Finot, Iván (2003). Descentralización y Participación en América Latina: Una mirada desde la economía, Boletín del ILPES/CEPAL, LC/IP/L, Santiago.

Font, Joan (2001), Ciudadanos y Decisiones Públicas, Editorial Ariel, Barcelona.

Hernández, José (2001). La descentralización, la participación y las nuevas tecnologías como elementos fundamentales de la gobernación democrática. Ponencia presentada en el Congreso Internacional del CLAD sobre la Reforma del Estado y de la Administración Pública, 6 (2001 Nov. 5-9: Buenos Aires)

Hood, Christopher; Jackson, Michael (1991). Administrative argument, Aldershot, Hants, England Brookfield, Vt., USA: Dartmouth Pub.

Huerta, María; Pressaco, Carlos; Ahumada, Consuelo; Velasco, Marcela; Puente, Jesús; Molina, Juan (2000), Descentralización, Municipio y participación ciudadana: Chile, Colombia y Guatemala, Centro Editorial Javeriano CEJA, Bogotá.

Inglehart, Ronald (1999). Globalization and Postmodern Values. The Washington Quaterly 23, pp 215-228.

Jones, Lawrence; Thompson, Fred (1999). Un modelo para la nueva gerencia pública: lecciones de la reforma de los sectores público y privado. Reforma y Democracia 15, Caracas, CLAD, pp. 233-276.
Kooiman, Jan (1993). Modern governance. New government-society interactions, London, Sage.

Mayntz, Renate (1993). Governing failure and the problem of governability. Some comments on a theoretical paradigm, en Kooiman, Jan (dir): Modern governance. New government-society interactions, London, Sage.

Mayntz, Renate (2001). El Estado y la sociedad civil en la gobernanza moderna, Reforma y Democracia, 21, Caracas, CLAD, pp. 7-22.

Mayntz, Renate (2002). Los Estados nacionales y la gobernanza global, Reforma y Democracia, 24, Caracas, CLAD, pp. 34-54.

Moore, Mark (1995). Creating Public Value: Strategic Management in Public Organizations, Harvard University Press, Cambridge, Massachusetts.

Osborne, David; Gaebler, Ted (1992). Reinventing government. How the entrepreneurial spirit is transforming the public sector. Traducción al español, Paidos, Barcelona (1994).

Prats, Joan (2003). El concepto y análisis de la gobernabilidad, Revista Instituciones y Desarrollo Número 14-15, Instituto Internacional de Gobernabilidad, Barcelona.

Ramió, Carles (2001). Los problemas de la implantación de la nueva gestión pública en las administraciones públicas latinas: modelo de Estado y cultura institucional, Reforma y Democracia, 21, Caracas, CLAD.

Ramírez, Enrique; Ramírez, Jesús (2004). Génesis y Desarrollo del concepto de Nueva gestión Pública. Bases Organizacionales para el replanteamiento de la acción administrativa y su impacto en la reforma del gobierno en David Arellano (compilador) Más allá de la reinvención del Gobierno: Fundamentos de la Nueva Gestión Públi- 
Gestión municipal participativa: Entre la nueva gerencia pública y la gobernanza ...

Montecinos, Egon

ca y presupuestos por resultados, Editado por CIDE y Cámara de Diputados de México.

Rhodes, Rod (1997). Understanding Governance. Policy Networks, Governance, Reflexivity and Accountability. Buckingham/Philadelphia: Open University Press.

Rufián, Dolores; Palma, Eduardo (1993). La Descentralización: Problema contemporáneo en América Latina, Dirección de Programas y Políticas Sociales, Instituto Latinoamericano y del Caribe de Planificación Económica y Social, ILPES/CEPAL.

Saidón, Osvaldo (1994). Redes. El lenguaje de los vínculos, Buenos Aires, Paidos, p. 294-302.

Santana, Leonardo; Negrón, Mario (1996). Reinventing Government: nueva retórica viejos problemas, Reforma y Democracia, Caracas, CLAD, pp. 147-164.

Subirats, Joan (2001). Nuevos Mecanismos Participativos y Democracia: promesas y amenazas en Font, Joan (2001):
Ciudadanos y Decisiones Públicas, Editorial Ariel, Barcelona.

Winograd, Morley (2002). La gobernanza en la Era de la Información. ¿Qué hacer y cómo hacerlo?, Reforma y Democracia, Caracas, Venezuela, 22, CLAD.

Whittingham, María Victoria (2005). Aportes de la teoría y la praxis para la nueva gobernanza, Reforma y Democracia, Caracas, Venezuela, 33, CLAD.

Ziccardi, Alicia (2009). La participación ciudadana del ámbito local. Fundamentos y Diseño de Espacios e Instrumentos en Delamaza, Gonzalo, et al. (2009), Gestión Municipal Participativa. Construyendo Democracia Cotidiana, editado por Corporación Innovación Ciudadana y Universidad de Los Lagos, Santiago.

Zurbriggen, Cristina (2004). Redes, actores e instituciones, Reforma y Democracia, Caracas, Venezuela, 30, CLAD. 
Gestión municipal participativa: Entre la nueva gerencia pública y la gobernanza ...

Montecinos, Egon

ca y presupuestos por resultados, Editado por CIDE y Cámara de Diputados de México.

Rhodes, Rod (1997). Understanding Governance. Policy Networks, Governance, Reflexivity and Accountability. Buckingham/Philadelphia: Open University Press.

Rufián, Dolores; Palma, Eduardo (1993). La Descentralización: Problema contemporáneo en América Latina, Dirección de Programas y Políticas Sociales, Instituto Latinoamericano y del Caribe de Planificación Económica y Social, ILPES/CEPAL.

Saidón, Osvaldo (1994). Redes. El lenguaje de los vínculos, Buenos Aires, Paidos, p. 294-302.

Santana, Leonardo; Negrón, Mario (1996). Reinventing Government: nueva retórica viejos problemas, Reforma y Democracia, Caracas, CLAD, pp. 147-164.

Subirats, Joan (2001). Nuevos Mecanismos Participativos y Democracia: promesas y amenazas en Font, Joan (2001):
Ciudadanos y Decisiones Públicas, Editorial Ariel, Barcelona.

Winograd, Morley (2002). La gobernanza en la Era de la Información. ¿Qué hacer y cómo hacerlo?, Reforma y Democracia, Caracas, Venezuela, 22, CLAD.

Whittingham, María Victoria (2005). Aportes de la teoría y la praxis para la nueva gobernanza, Reforma y Democracia, Caracas, Venezuela, 33, CLAD.

Ziccardi, Alicia (2009). La participación ciudadana del ámbito local. Fundamentos y Diseño de Espacios e Instrumentos en Delamaza, Gonzalo, et al. (2009), Gestión Municipal Participativa. Construyendo Democracia Cotidiana, editado por Corporación Innovación Ciudadana y Universidad de Los Lagos, Santiago.

Zurbriggen, Cristina (2004). Redes, actores e instituciones, Reforma y Democracia, Caracas, Venezuela, 30, CLAD. 